\title{
Quality Cost in Saudi Arabia Plastic and Glass Industry
}

\author{
Hussein Reda ${ }^{1} \&$ Mohammad Kanan ${ }^{1}$ \\ ${ }^{1}$ Industrial Engineering Department, College of Engineering University of Business and Technology, Jeddah, \\ KSA \\ Correspondence: Hussein Reda, Industrial Engineering Department, College of Engineering University of \\ Business and Technology, Jeddah, KSA. E-mail: hreda@ubt.edu.sa
}

Received: December 3, 2017

Accepted: January 24, 2018 Online Published: January 26, 2018

doi:10.5539/emr.v7n1p27

URL: http://doi.org/10.5539/emr.v7n1p27

\begin{abstract}
Quality costs are those resulting from producing, identifying, repairing, and avoiding defective products. Quality costs consist of the following four categories Internal costs, failure costs, external failure costs, and appraisal costs. A survey of several plastic and glass industries in Saudi Arabia is conducted. The survey includes a cross representation of manufacturing activities existing in the region. The survey is intended to assess the level of awareness and quantitative estimates of quality costs as related to the plastic and glass industries. The survey design and findings are presented along with analysis. Specific conclusions are drawn regarding quality costs studies and reduction/improvements programs as related to the surveyed industry category.
\end{abstract}

Keywords: TQM, plastic and glass industry, quality cost, quality improvement

\section{Introduction}

Quality costs are those resulting from producing, identifying, repairing, and avoiding defective products. The following four categories are used to define and quantify manufacturing quality costs. A survey of plastic and glass industries in Saudi Arabia is conducted. The survey includes a cross representation of manufacturing activities existing in the region. The survey is intended to assess the level of awareness and quantitative estimates of quality costs as related to the above four categories. The survey design and findings are presented along with analysis. Specific conclusions are drawn regarding quality costs studies and reduction/improvements programs as related to the surveyed industry categories.

\section{Literature Review}

In process improvement efforts, cost of quality is a concept used to measure the overall cost of non-quality conformance result's and deficiencies. Cost of quality was initially defined by A. Feigenbaum in a review paper published by Harvard Business Review in 1956 (Feigenbaum, 1956). However, the earlier understanding of quality cost was that better quality requires more costs that may be achieved through the use of higher quality raw materials or more advanced machines and through employing highly experienced workers (Feigenbaum, 1991). In addition, the traditional practice of cost accounting categories any financial costs into revenues, expenses, and changes in shareholder equity. However, it did not provide any classification for the costs resulting from quality deficiencies. This exclusion of quality costs turned out to be critical due to the fact that the concerned parties dealing with the manufacturing process have no direct exposures to the products (Crosby, 1979). On the other hand, re defining the factors affecting product quality into the traditional financial books allows managers and quality personnel to better asses the firm's investments in quality and to tie it more closely to their quality improvement and cost reduction efforts (Arnold, 1994).

The classical approach towards the improvement of quality is based on the concept that the more investment in inspection and testing will result in higher amounts of saving in quality defects and associated inspection efforts. Feigenbaum's classification permits the concerned parties to utilize these costs for their own benefits (Feigenbaum, 1991). Furthermore, firms usually resort to install more measures of control and appraisal when they are faced with increased rates of rejected parts. However, this increase in appraisal effort does not guarantee reduction of the failure costs. The other possible option is to invest more in the prevention cost in order to reduce if not eliminate the failure causes and eventually cost. Thus classification of quality costs would provide a quantified foundation for measuring, monitoring, and forecasting quality (Feigenbaum, 1991). Other and additional forms of quality costs principles can be found in the concept of the cost of poor quality which was 
developed and described by Juran on quality cost accounting (Juran, 1962). A paper titled "Hidden quality costs and the distinction between quality cost and quality loss" (Georgios et al., 2001), suggests that there are other types of quality costs other than prevention, appraisal and failure costs. These are considered hidden costs and they are described that study. The significance of these costs is the manufacturing defects and the design malfunctioning are overlooked because they are considered too large to be calculated.

Furthermore, prevention, appraisal and failure are categories as quality costs and quality losses. So, it introduces the classification of defects avoidance and inspection loss.

Many organizations encounter nowadays the inefficiency of majority of cost- accounting formats in recording and measuring quality costs and in providing suitable framework that covers total quality cost. The major factor for this failure is absence of formal tools for measuring the financial results of low quality that are the product of many quality tasks.

A paper titled "Improving the definition and quantification of quality costs" (Ching-Chow, 2008) presents a study that discuss the emerging trends by redefining the classical 'Prevention, Appraisal, and Failure' classification of quality costs and the unclear costs that comes from the emerging of a couple of hidden types of costs, namely the "extra resultant cost" and the "estimated hidden cost". Adopting these emerging classification, this paper presents a comprehensive categorization of the components of the cost of quality with reference to an elaborate list of quality tasks in addition to the concept of "product life-cycle". The paper also explains how to measure the different types of quality costs using various methods based on what it calls "cost of quality account matrix". This method consists of measuring the relevant percentage of accountabilities for the quality costs that each group of activities share.

Navee Chiadamrong in his paper titled "The development of an economic quality cost model" (Navee, 2003) indicates that the meaning of the word "economics of quality" extends far beyond the commonly understood meaning of "quality cost". Usually, whenever a rework job is done or when an effort is conducted to sort out defects, the cost of quality increases. Nevertheless, the costs of resolving these issues extends far more than the obvious costs of the tasks of appraisal and inspection. Traditional practice of cost accounting does not provide solutions to organizations that they can resort to quantify quality cost data because of its shortage to measure the hidden and specifically, unrecognized costs. Therefore, it is not possible to measure extra costs. This study describes a classical model of quality economics in relation to two major factors, namely the classical prevention, appraisal, failure costs and the invisible quality loss costs. This method considers that process costs permits for the tracing of the costs that are usually result from production process itself and to the costs that are related to quality. Thus this model would help organizations to have a more defined frame for total quality costs.

Also, a paper by Plunkett and Dale titled "Quality costs: a critique of some economic cost of quality models" (Plunkett \& Dale, 1988) provides a review of several quality costs surveys that were carried out in several regions. Limited number of these surveys covered extended dimensions on cost of quality however, the majority of the other surveys dealt with cost of quality in general management style dealing with it in a general and wide scope covering financial factors and assessment of management behaviors. One section of the study dealt with matters concerned with data gathering, measuring, analysis and utilization of quality cost information. Another section of the paper dealt with matters related to classical evidence of interactions among cost of quality items.

A survey study of Quality tools used in the Food industry in Saudi Arabia was conducted. Its findings were presented by the paper published by Naser (2007). The food industry in Saudi Arabia is facing many challenges that stem from aggressive competition from multinational food companies. However, this industry have continuously made marketable levels of growth exemplified by its higher rate of exportations. The challenge is increased due to the subscription of Saudi Arabia to the "World Trade Organization Agreement". This paper discusses the status of quality in Saudi food firms and its ability to face up to the emerging competition and asses its chances to successfully face up the new realities of the world market. The study further examined the utilization of the quality models in the processing activities of the food making organizations. It explored the tools of Total Quality Management and it is applied to measure these firms' capabilities and performance. Many examples that are reflective of the Saudi's food firms were presented. These findings were supported by a prototype survey which included some market data to quantify the quality status of the companies. The findings were presented in statistical models and a discussion of its validity were presented. It showed that some measures of the use of total quality management fundamentals activities were practiced. It also showed that other highly developed quality tools are in use in some of the food firms in Saudi Arabia. Additional results showed continued inspirations of the food industry to achieve world class recognition and quality awards. A review of research on cost of quality models and best practices was presented by Andrea and Vince (2006). In their paper, 
they presented a summary of published articles dealt with multiple topics related to the cost of quality models. It discusses their effectiveness in measuring the quality cost of quality methods. The study reviewed and discussed the issues surrounding quality costing approaches. Their finding indicates that although the publication summary indicates a growing attention of the surveyed researchers on the cost of quality quantifications modeling and the importance of including it in all of the quality management research. The survey also indicated that many organizations actually apply such models and consequently are making progress in lowering the cost of quality while increasing customer's satisfaction.

In this research, a survey study was conducted to measure the cost of poor quality in Saudi Arabia plastics and glass industry. This study targeted 48 affiliations, where 19 affiliations responded, five of them were excluded due to incomplete/erroneous responses.

\section{Research Methodology}

The objective of this study is to assess the status of poor quality in Saudi plastic and glass industries. In order to achieve this goal, a questionnaire was designed and conducted online to related people. Data of this questionnaire covered the following aspects:

\subsection{Internal Cost}

Costs refer to these costs incurred prior to the product delivery to the customer. They include costs resulting from scrap, rework, retest, downtime, yield losses or disposition.

\subsection{External Failure}

Costs refer to these costs occurring after the products are delivered to the customer. They include categories such as complaint adjustment, returned products, warranty charges, and liability or allowances concessions.

\subsection{Appraisal Cost}

Appraisal costs are those resulting from measuring, evaluating, and auditing of material and products to determine their condition and conformance to specifications. They include costs of inspection and testing of incoming material and through production, associated material and services consumed, and instruments and testing equipment calibration.

\subsection{Preventive Costs}

Preventive costs are these associated with activities aimed at reducing appraisal and failure costs. They include costs of quality planning and design, new products review, process control, training, quality data acquisition, analysis and reporting, and improvement projects.

Cost of poor quality is measured as the sum of all costs such as inspection cost, training cost, cost of scrap, cost of rework, and cost of return. Results show that the annual average cost of poor quality is $7.0145 \%$ and is categorized as in Figure 1.
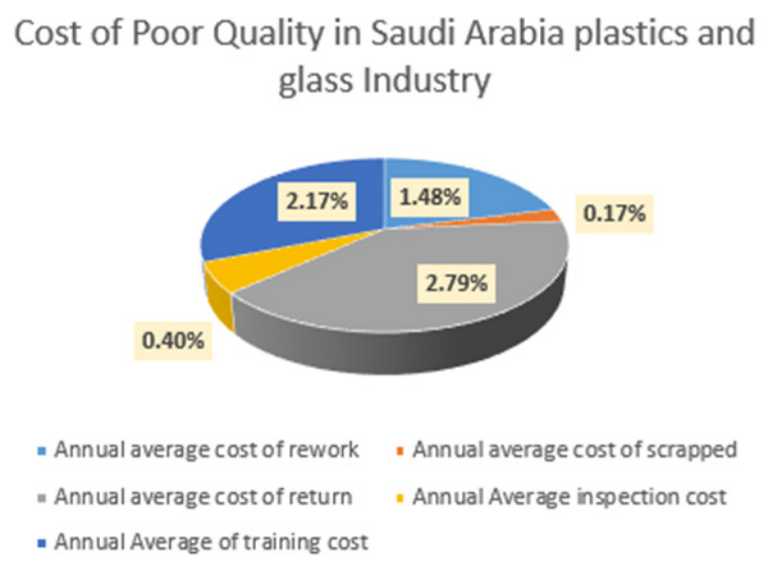

Figure 1. Average annual cost of poor quality

Providing a high level of quality products is not costly. In fact, in many cases, it is less expensive. In addition, when applying quality concepts and methodologies, cost and scheduling problem will be reduced. Executive 
officers have to take more considerations on putting quality first in every decision.

Cost of poor quality varies from one affiliation to the next. This variation depends on many factors such as Product complexity, technology used, how customers use the product, elements of quality costs included, and the level of refinement of the quality system (Harrington, 1999).

\section{Summary and Major Findings}

Through the previous discussion of the questionnaire, plastic and glass industry faces real problem related to the cost of poor quality. This study has found that the annual average cost of rework is $1.48 \%$, annual average cost of scrapped is 0.17 , annual average cost of return has the highest percentage of $2.79 \%$, annual average of inspection cost is $0.4 \%$, and the annual average of training cost is $2.17 \%$. These costs resulted be the lack of quality knowledge aspects in this industry. Technicians have to get more training on how to reduce waste and increase productivity. These companies showed keep periodic maintenance tables and machine breakdown records.

\section{References}

Andrea, S., \& Vince, T. (2006). A review of research on cost of quality models and best practices. International Journal of Quality and Reliability Management, 23(6), 647-669. https://doi.org/10.1108/02656710610672470

Arnold, K. L. (1994). The Manager's Guide to ISO 9000 (p. 24). New York: Free Press.

Ching-Chow, Y. (2008). Improving the definition and quantification of quality costs. Total Quality Management Business Excellence, 19(3), 175-191. https://doi.org/10.1080/14783360701600563

Crosby, P. B. (1979). Quality Is Free (p. 121). New York: McGraw-Hill.

Feigenbaum, A. V. (1991). Total Quality Control (3rd ed.) (p. 109). New York: McGraw-Hill.

Feigenbaum, A. V. (1991). Total Quality Control (3d ed.) (pp. 111-113). New York, New York: McGraw-Hill.

Feigenbaum, A. V. (1991). Total Quality Control (3rd ed.) (pp. 130-131). New York, New York: McGraw-Hill.

Feigenbaum, A. V. (November-December 1956). Total Quality Control. Harvard Business Review, 34(6).

Georgios, G., Takao, E., \& Kazuhiko, W. (2001). Hidden quality costs and the distinction between quality cost and quality loss. Total Quality Management and Business Excellence, 12(2), 179-190. https://doi.org/10.1080/09544120120011406

Harrington, H. J. (1999). Cost of Poor Quality. International Journal of Strategic Cost Managemen, 17.

Juran, J. M. (1962). Quality Control Handbook (2nd ed.) (pp. 1-38-1-39). New York: McGraw-Hill.

Naser, A. A. (2007). Application of quality tools by the Saudi food industry. The TQM Magazine, 19(2), 150-161. https://doi.org/10.1108/09544780710729999

Navee, C. (2003). The development of an economic quality cost model. Total Quality Management and Business Excellence, 14(9), 999-1014. https://doi.org/10.1080/1478336032000090914

Plunkett, J. J., \& Dale, B. G. (1998). Quality costs: a critique of some economic cost of quality models. International Journal of Production Research, 26(11), 1713-1726. https://doi.org/10.1080/00207548808947986

\section{Copyrights}

Copyright for this article is retained by the author(s), with first publication rights granted to the journal.

This is an open-access article distributed under the terms and conditions of the Creative Commons Attribution license (http://creativecommons.org/licenses/by/4.0/). 